Kristina Stanojević1, Dragana Makajić-Nikolić1, Goran Radovanović

${ }^{1}$ University of Belgrade, Faculty of Organizational Sciences, Serbia

${ }^{2}$ Ministry of Defence, University of Defence Belgrade, Serbia

\title{
Optimization of the Financing of the Raw Material Inventories: Case Study
}

DOI: 10.7595/management.fon.2021.0005

Abstract:

Research Question: Optimal financing of the raw material inventories in the copper processing industry is perceived as a problem of choosing the financing sources and determining the purchase dynamics. Motivation: The company can realize the financing of raw material inventories from multiple sources under various conditions. The company efforts should be aimed at reducing the total costs that can occur in the process of purchase. Each company should simultaneously strive to satisfy the demand, but also to avoid keeping the excess of cash assets in inventories. Idea: The core idea of this paper is to evaluate the optimal financing of raw material inventories by the usage of the mathematical model that refers to the determination of financing sources, from which the required assets should be borrowed. Data: For the purpose of the case study example, the data used in the paper are approximations of information from the company and metal stock exchange. Tools: Excel was used to predict demand, while GLPK programme (GNU Linear Programming Kit) was used for the optimization of the defined model. Findings: The paper defines an optimization problem for determination of the financial sources, optimal periods, and the number of assets that will be used from these sources to secure continuity of the production process with minimum purchase costs. The paper also formulates a mathematical model of this problem and then illustrates it on the example of the real-life company for copper processing. Contribution: The results of this study show that such analysis gives the decision-makers a better insight into the possible scenarios while the final decision depends on their assessment, flexibility, attitude towards risk, need for security, etc.

Keywords: inventories management, short-term financing, linear programming, raw material, industry of copper processing.

JEL Classification: C61, D25

\section{Introduction}

Financial and operative decisions within the companies are mutually dependent because the appropriate amounts of monetary assets enable good operative decisions which further affect the assets and financial balance of the company (Babich \& Sobel, 2004; Caniato, Henke, \& Zsidisin, 2019). The same applies to the case of inventory management which represents an important segment of the company's production business and its performance (Song \& Song, 2009). Market and demand unpredictability, together with the unnecessary cost of keeping a high level of inventories require special attention. This characteristic of both the market and demand can be reduced by proper analysis and prediction since the management of inventories directly depends on demand prediction (Atanasov, Rakicevic, Lecic-Cvetkovic \& OmerbegovicBijelovic, 2014). The aspirations of the company should be aimed at the determination of optimal quantities of inventories, more precisely, minimally required for adequate functioning of the company (Lai, Debo \& Sycara, 2009). From the financial point of view, keeping a too high or a too low level of inventories has a negative influence on a business (Abbasi, Wang, \& Abbasi, 2017). In the former case, there are substantial costs of the capital blocked in inventories, which implies large interests or opportunity costs, storage and security costs, etc. In the latter case, a shortage of inventories leads to business losses due to production halt and loss of position in the chain of supply (Basu \& Wright, 2010). Also, financing opportunities can influence decisions about inventory levels (Chod, 2016; Marak \& Pillai, 2019). 
The existing literature offers a large number of studies related to the correlation of financial and operative decisions and the inclusion of financial elements in inventory management (Jing \& Seidmann, 2014; Zhi, Wang, \& Xu, 2020). Often, a typical EOQ model is extended by financial elements such as loan period and discount (Sana \& Chaudhuri, 2008) or by the inclusion of various types of loan policies (Dye, 2012). Chen, Kok and Tong (2013) investigate how options of financing affect the decisions on inventory levels. A problem of inventory financing is less observed in the literature and the related publications are mostly of recent date. Gong, Chao and Simchi-Levi (2014) observe the problem of short-term inventory financing and solve it using dynamic programming; Dada and Hu (2008) extend the model of newsvendor problem by costs of borrowing cash assets for financing the optimal quantity purchase; Buzacott and Zhang (2004) implement financial constraint within the model for decision-making on production and inventories; Chen and Teng (2015) carry out the analysis of cash flow within the decision-making on inventory loan; Yang and Birge (2013) developed a model for determination of optimal portfolio for inventory financing, which consists of several sources: cash, commercial loans and short-term loans; Moussawi-Haidar and Jaber (2013) developed a mathematical model which simultaneously determines the amount of money that the company should possess, the amount that should be invested in financial security and the amount that should be borrowed to finance the inventories; Chen, Zhao and Su (2017) introduced an inventory model for raw materials with price fluctuations with the goal to minimize total costs; Katehakis, Melamed and Shi (2016) consider operative and financial policy of the company, which should determine the amount of cash assets that should be borrowed for financing the inventories, while Kouvelis and Zhao (2012) developed a model for determination whether purchase financing is more profitable by supplier or by bank loans.

The subject of this paper is the optimal financing of raw material inventories. The approach that will be presented in the paper can contribute to better inventory management in the metal processing industry in which the entire production depends on the availability of the main raw material. Given that this industry is characterized by large-scale production, which requires a large amount of raw materials, companies are often faced with the problem of liquidity. Consequently, inventory management is largely related to the problem of liquidity resolution. In our approach, needs for inventories are expressed in money and the problem which is modelled and solved refers to the determination of financing sources, from which the required assets should be borrowed. The original mathematical model for optimization of raw material purchasing in copper processing industry is formulated based on the model of short-term financing optimization (Cornuejols, Pena, \& Tutuncu, 2018; Sana, Ferro-Correa, Quintero, \& Amaya, 2018). By including fixed purchasing and transportation costs into the model, the optimal solution refers not only to the choice of sources and dynamics of financing, but also to the amount and dynamics of procurement of raw materials, i.e., to inventory management.

\section{Mathematical Model Formulation}

The specificity of this problem is that copper is primarily a stock exchange good, therefore the price of this raw material changes daily and is highly dependent on different macroeconomic impacts (Willing, 2020). Companies within this branch of industry need to keep the inventories of this raw material on the optimal level. Management of inventories in this paper will be observed through short-term purchase financing of this raw material. They can ensure the financing of raw materials' purchasing from various sources. It is important to provide the liquidity of the company because the lack of it represents one of the significant risks which can cause production delay (Njegomir \& Demko-Rihter, 2015). It is important to determine where from, how much, and when to ensure cash assets, with minimum costs of interests and orders.

For the defined problem, an original mathematical model of optimal financing of the inventories has been formulated. In each of the observed periods, it is necessary to determine the quantities of copper needed, the amount of cash assets for financing this purchase, as well as the sources which will finance this purchase. Considering that the company deals with copper processing only, and not with its trading, it should aim to predict and plan the necessary amounts of this raw material and then to determine the necessary cash assets for its purchase.

For each period, the amount of raw materials necessary to satisfy buyers ' demands can be predicted, and it can be obtained either from the purchase or from the inventories. The purchased amount of raw materials will be smaller than needed, if there is already a certain amount in stock from the previous period, or larger, when an excess of raw materials should remain in stock for the next period. Possible excess of raw materials is limited since the maximum level of inventories is defined.

Based on quantities of raw materials needed and their purchase cost, the cash flow for the observed period is determined (Huff \& Rogers, 2015). In this paper, we assume that cooper prices can be satisfactory predicted (Buncic \& Moretto, 2015). Every source of financing has different conditions for financing and 
different interest rates, which in this case represents one of the costs of the purchase (Pal, Sana \& Chaudhuri, 2014). Besides these costs, the specificity of copper as stock exchange goods is also characterised by the costs of the stock market agent per tonne of copper and the premium costs, as well as fixed customary purchase costs.

For the observed problem, the mathematical model is formulated which determines the dynamics of raw material purchase, optimal combinations of short-term financial sources of purchase, and the amount of cash assets that provide minimum costs. The following notation was used:

- $N=\{1, \ldots, n\}$ - set of the period;

- $F=\{1, \ldots, m\}$ - set of financing assets;

- $N_{p}=\{2, \ldots, n\}$ - the subset of the period starting from the second.

- $d$ - additional unit purchase cost (fixed cost of purchase per tonne of copper/price of copper per tonne;

- $a$ - the maximum level of inventories;

- $c$ - correction quotient;

- $p_{i}$ - need for cash assets in $i$-th period, $i \in N$;

- $b_{i j}$ - the maximum amount of assets in $i$-th period from $j$-th financing source, $i \in N, j \in F$;

- $k_{j}$ - interest for $j$-th financing source, $j \in F$;

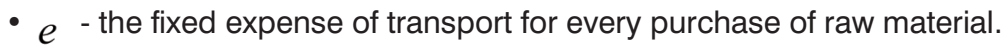

- $x_{i j}$ - amount of financing in $i$-th period from $j$-th financing source, $i \in N, j \in F$;

- $z_{i}$ - amount of inventories in $i$-th period, $i \in N$;

$y_{i}=\left\{\begin{array}{ll}1 & \text { if the purchase exists in } i \text {-th period } \\ 0 & \text { otherwise }\end{array}, i \in N\right.$

The mathematical model of the described problem has the following form:

$$
\begin{gathered}
\min _{i \in N}\left(\sum_{j \in F}(d) \cdot x_{i j}+\sum_{j \in F} k_{j} \cdot x_{i j}+e \cdot y_{i}\right) \\
\text { s.t. } \\
(1-d) \cdot \sum_{j \in F} x_{1 j}-\sum_{j \in F}\left(k_{j} \cdot x_{1 j}\right)-z_{1}-e \cdot y_{1}=p_{1} \\
(1-d) \cdot \sum_{j \in F} x_{i j}-\sum_{j \in F}\left(k_{j} \cdot x_{i j}\right)-z_{i}+z_{i-1}-e \cdot y_{1}=p_{i}, i \in N_{p} \\
x_{i j} \leq b_{i j}, i \in N, j \in F \\
\quad z_{i} \leq a, i \in N \\
c \cdot \sum_{j \in F} x_{i j}-y_{i} \leq 0, i \in N \\
x_{i j}, z_{i} \geq 0, y_{i} \in\{0,1\}, i \in N, j \in F
\end{gathered}
$$


The objective function (1) represents total additional costs that occur with the ordering of the raw materials in all observed periods, including: costs that occur with each order and depend on the ordered amount, interest costs which depend on chosen financing source and fixed ordering costs. The first constraint (2) refers to the first period and ensures that the total sum of assets from all financing sources, reduced for interest costs, costs which occur in order, fixed costs of ordering, and excess that remains on inventories, equals the necessary amount of assets in the first period. The second constraint (3) is related to remaining periods and in contrast to the first period comprises also the amount which remained in inventories in the previous period and is available in the observed period. The third constraint (4) represents the maximum amount of assets that can be ensured in each of the periods, depending on the financing source. The fFourth constraint (5) refers to the maximum amount of inventories, whereas the fifth constraint (6) connects the variable that represents a decision on purchase and the variable that represents the amount of acquired cash assets.

\section{Results}

The proposed approach will be illustrated on the example of the company in the Republic of Serbia as a case study. In this industry, the most common method of obtaining financial resources is short-term financing methods which are further analysed in the following scenarios. Before the formulation of the mathematical model, the prediction of necessary quantities of copper has been carried out, for the intended period within which the optimization is performed. Out of the total range of products, ten selected products were included in the analysis. The observed period was 31 days, within which the necessary amount of raw material was determined for each day, hence the cash flow, i.e., the amount of necessary cash assets from the available financial sources.

For the prediction of demand, three forecasting methods were used, as follows: Moving average, Exponential smoothing, and Linear trend (Stevenson, 2005). The only purchase observed is the purchase of copper for selected products. The demands for selected products, realised in the previous two months, more precisely within 61 days, were observed. The three mentioned forecasting methods were evaluated by mean square error. Since the best method in $70 \%$ of the products was the method of a linear trend and the differences in errors with other products were insignificant, the chosen method for prediction of all ten products was the method of a linear trend.

Based on the obtained predicted quantities, the total amount of raw materials that are necessary to purchase from the supplier every day was determined. Based on the average price of copper, the amount of money needed for financing of raw materials was calculated. The part of the obtained values is shown in Table 1.

Table 1: Predicted required quantities of raw materials and cash assets

\begin{tabular}{|c|c|c|}
\hline Period & Predicted quantity [t] & Required cash assets [\$] \\
$\mathbf{1}$ & 39.35109 & 196,755 \\
$\mathbf{2}$ & 39.20327 & 196,016 \\
$\mathbf{3}$ & 39.05545 & 195,277 \\
$\mathbf{4}$ & 38.90762 & 194,538 \\
$\mathbf{5}$ & 38.75980 & 193,799 \\
$\mathbf{6}$ & 38.61198 & 193,059 \\
$\mathbf{7}$ & 38.46415 & 192,320 \\
$\ldots$ & $\ldots$ & $\ldots$ \\
$\mathbf{2 6}$ & 35.65551 & 178,277 \\
$\mathbf{2 7}$ & 35.50769 & 177,538 \\
$\mathbf{2 8}$ & 35.35986 & 176,799 \\
$\mathbf{2 9}$ & 35.21204 & 176,060 \\
$\mathbf{3 0}$ & 35.06422 & 175,321 \\
$\mathbf{3 1}$ & 34.91639 & 174,581 \\
\hline
\end{tabular}

As a source of financing for its raw materials the company has factoring and advance payment. Factoring represents a financial service by which the companies sell their invoices. A factor is a person, most often banks or agencies, specialised for this kind of business, that buys out the invoice. Thus a client sells the invoice to the factor before its due date and the factor pays the invoice at the time of taking over the debt with a certain commission (Lekkakos \& Serrano, 2016). The advance payment refers to the payment process where the delivery of the goods is carried out after the executed payment. It is most often applied to products (services) that imply certain specifications from the buyer`s side (Zhang, Dong, Luo, \& Segerstedt, 2014). The additional condition in the observed period was that, if there is an advance payment, it can make, on 
average, $40 \%$ at the most, out of total necessary assets. Besides, there were ten days when the advance payment was not possible.

In the actual example, cash assets can be secured from the mentioned sources under the following conditions:

1. The maximum amount of assets secured by factoring, which can be paid in one period is $300,000 \$$, with $3 \%$ interest;

2. The maximum amount of assets that can be realised by advance payments in available periods is $66,000 \$$.

The costs that are incurred in ordering the raw materials and that depend on the ordered amount are $120 \$ / \mathrm{t}$. These costs comprise payment of the stock exchange agent per tonne of copper and commission payment per tonne of copper. Besides, there are fixed ordering costs that are $\$ 3,000$ per order.

In the case of a surplus of cash assets in a certain period, the excess is considered as a balance of raw materials on inventories. The maximum amount that can be found on inventories is $50 t$, consequently, the maximum value of raw materials on inventories is $\$ 250,000$.

A formulated mathematical model was solved using GLPK programme (GNU Linear Programming Kit, 2012).

Based on optimization results of the initial state, the total minimum costs of the purchase of raw materials are $\$ 356,331.24$. The optimal solution represents quantities of assets that need to be funded by factoring and advance payment. Table 2 shows the amount of assets per source of financing in each of the periods. The maximum amount of assets that can be obtained from the source of factoring was taken 12 times, whereas, for the remaining six periods, the assets taken were smaller than the maximum allowed. The advance payment occurred 14 times in the observed time and each of the periods the maximum available amount of cash assets was used. The total amount of assets obtained by factoring and advance payment are $\$ 5,188,060$ and $\$ 924,000$, respectively. The inventories at the end of the observed period equal zero, whereas during a time, the amount of inventories changes (Table 3 ).

\section{Scenario 1}

To achieve an even greater security regarding the financing of the raw materials, the company can also use commercial papers, which could also make purchase financing possible. In this case, the same assumptions are valid as in the initial state, except that, in addition to sources 1. and 2., there is one more extra source of financing:

3. The maximum amount of money that can be gained with the help of commercial papers is $\$ 250,000$, with a $10 \%$ interest rate.

In this scenario, the minimum total costs are $\$ 350,456.5928$. It is necessary to ensure the maximum available amount of assets for 11 periods by factoring, whereas for the remaining three periods the ensured assets are smaller than the maximum allowed. The advance payment is used completely in a total of 16 periods. The assets from commercial papers are obtained for four periods. The total amount of assets that have to be obtained by factoring, advance payment, and commercial papers are $\$ 4,916,043, \$ 1,056,000$, and $\$ 69,728$, respectively. In the observed period, the raw materials should be ordered 17 times. It is necessary to form inventories during time so that they are not ordered in each period, but they should best be spent in the last observed period. Table 2 shows the amount of assets per each source of financing, whereas Table 3 shows raw material inventories levels.

\section{Scenario 2}

To provide larger flexibility regarding inventories that are at the company`s disposal, the company holds $\$ 200,000$ worth of inventories/40t, that are placed at production disposal at the beginning of each month. In order to secure itself for the following month, the company must control these inventories to ensure the same amount of inventories at the end of each month that can be used in the following month.

Sources that the company now has at its disposal, by which these needs can be satisfied with sources 1 . and 2. as well as:

4. Inventories of the company itself were observed as a source of financing - $\$ 200,000$ worth/40t, for the whole observed period.

By using its own inventories as the source, the company has no interest costs, but it has an obligation at the end of the month to provide the same or larger amount of inventories than those that existed at the beginning of the month. 
The introduction of its own inventories requires a change in constraints of the mathematical model. This change appears at constraint (2) which refers to the first period, to which company `s own inventories are added on the left side of constraint and a new constraint is added (8) which refers to the amounts of inventories $z_{n}$ which have to be larger or equal to the quantities of company's own inventories $h$ which were at disposal at the beginning of the observed period.

$$
\begin{gathered}
(1-d) \cdot \sum_{j \in I} x_{1 j}-\sum_{j \in I}\left(k_{j} \cdot x_{1 j}\right)-z_{1}-e \cdot y_{1}+h=p_{1} \\
z_{n} \geq h
\end{gathered}
$$

In this scenario, the minimal additional costs are $\$ 357,409.452$. Financing sources and the amount of cash assets per period are shown in Table 2 . It is necessary to order raw materials 19 times. All available assets from factoring should be used within 11 periods and within seven periods only a part of available assets. For 15 periods it is necessary to obtain all available assets by advance payment. Using factoring, it is necessary to obtain $\$ 5,123,138$, whereas by advance payment the amount is $\$ 990,000$. The amount of raw materials in inventories are changeable during a time, but eventually, they come down to the minimum. At the end of the observed period, the inventories are precisely $40 \mathrm{t}(\$ 200,000)$, although they are permitted to be larger (Table 3).

\begin{tabular}{|c|c|c|c|c|c|c|c|}
\hline \multirow{2}{*}{ Period } & \multicolumn{2}{|c|}{ Initial state } & \multicolumn{3}{|c|}{ Scenario 1} & \multicolumn{2}{|c|}{ Scenario 2} \\
\hline & Factoring & Advance & Factoring & Advance & Commercial papers & Factoring & Advance \\
\hline 1 & 300,000 & 66,000 & 249,619 & 66,000 & & 195,919 & 66,000 \\
\hline 2 & 237,355 & 66,000 & 300,000 & & & 130,020 & 66,000 \\
\hline 3 & & & & & & & \\
\hline 4 & 300,000 & 66,000 & 300,000 & 66,000 & 32,606 & 300,000 & 66,000 \\
\hline 5 & & & & & & & \\
\hline 6 & 241,806 & 66,000 & 300,000 & 66,000 & & 241,806 & 66,000 \\
\hline 7 & 300,000 & 66,000 & & & & 300,000 & 66,000 \\
\hline$\ldots$ & $\ldots$ & $\ldots$ & $\ldots$ & $\ldots$ & $\ldots$ & $\ldots$ & $\ldots$ \\
\hline 26 & 300,000 & & 300,000 & 66,000 & & & \\
\hline 27 & & & & & & 300,000 & 66,000 \\
\hline 28 & 300,000 & 66,000 & 300,000 & 66,000 & & & \\
\hline 29 & & & & & & 300,000 & 66,000 \\
\hline 30 & 300,000 & 66,000 & 300,000 & 66,000 & & & \\
\hline 31 & & & & & & 271,385 & 66,000 \\
\hline
\end{tabular}

Table 2: Amount of assets obtained depending on the source of financing, in dollars

Table 3: Inventory level, in dollars

\begin{tabular}{|c|c|c|c|}
\hline Period & Initial state & Scenario 1 & Scenario 2 \\
\hline 1 & 148,461 & 100,800 & 250,000 \\
2 & 238,398 & 250,000 & 238,398 \\
3 & 43,121 & 54,722 & 43,121 \\
4 & 193,799 & 233,946 & 193,799 \\
5 & & 40,164 & \\
6 & 97,104 & 192,321 & 97,104 \\
7 & 250,000 & & 250,000 \\
$\ldots$ & $\ldots$ & $\ldots$ & $\ldots$ \\
26 & 189,869 & 189,869 & 71,722 \\
27 & 12,330 & 12,330 & 239,400 \\
28 & 180,747 & 180,747 & 62,600 \\
29 & 4,687 & 4,687 & 231,756 \\
30 & 174,582 & 174,582 & 56,435 \\
31 & & & 200,000 \\
\hline
\end{tabular}




\section{Discussion}

Progress of the inventories level can be compared for three observed scenarios (Figure 1).

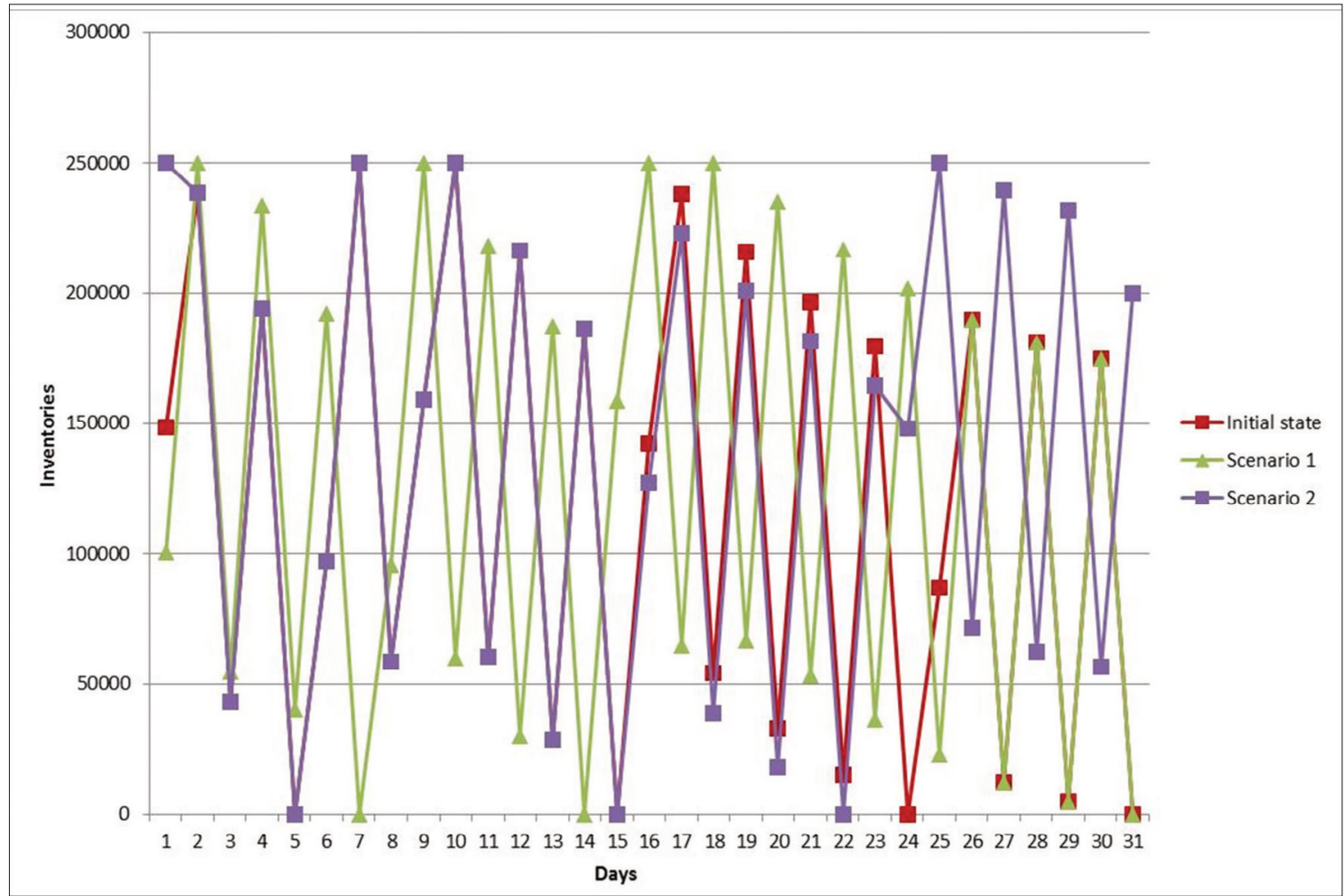

Figure 1: Representation of inventories levels

Total costs for each of the presented cases are shown in Table 4.

Table 4: Optimal solutions gained, in dollars

\begin{tabular}{|c|c|c|c|}
\hline Scenario & Initial state & Scenario 1 & Scenario 2 \\
\hline Minimum costs & $356,331.24$ & $350,456.5928$ & $357,409.452$ \\
\hline
\end{tabular}

Additional source of financing, such as commercial papers, provides lower costs, besides offering the company certain flexibility regarding the options for managing available assets and greater insurance from the delay and shortage of inventories. If the company decides to have its own inventories, the costs will be higher than in two other cases. The company with its own inventories has certain flexibility in decisionmaking and yet does not create a larger increase in costs in comparison with the initial state where there are no preliminary inventories.

The total cash assets necessary for each of the financing sources are shown in Table 5.

Table 5: The total necessary cash assets, depending on financing source, in dollars

\begin{tabular}{|c|c|c|c|}
\hline Scenario & Initial state & Scenario 1 & Scenario 2 \\
\hline Factoring & $5,188,060$ & $4,916,043$ & $5,123,138$ \\
Advance payment & 924,000 & $1,056,000$ & 990,000 \\
Commercial papers & $/$ & 69,728 & $/$ \\
Total & $6,112,060$ & $6,041,771$ & $6,113,138$ \\
\hline
\end{tabular}

The company obtained the largest amount of necessary cash assets by factoring, in all three cases. The major amount of cash assets by factoring will be used in the initial state, whereas the option of the advance payment will be used less than in the two other scenarios. The largest amount of total resources borrowed appears in Scenario 2 and the smallest in Scenario 1. 
The total number of purchases in the initial state, Scenario 1 and Scenario 2 is 18, 17, and 19, respectively. In Scenario 1, the number of orders is the smallest, which is positive, since each order has its own fixed cost. Besides, Scenario 1 mostly uses the option of the advance payment, which is also positive, because this option of financing does not require paying the interest. Scenario 1 requires the smallest amount of total necessary assets and generates the lowest additional costs, which is a consequence of financing from the additional source in comparison with two other scenarios, which enables greater flexibility.

The suitability of using the proposed model in examining different scenarios is obvious. However, its biggest contribution is that it combines the costs of borrowing finance to maintain liquidity and the cost of purchasing raw materials. As can be seen from the results of the scenario, there are days when companies should not borrow money, i.e., they should not purchase raw materials. In this way, financial decision making and decision making related to inventory management were combined, which was the goal given the interdependence of these decisions.

\section{Conclusion}

The subject of this paper is the optimal financing of raw material inventories in the industry of copper processing. The problem of determination of financing assets necessary to the company, sources from which these assets should be obtained and the periods within which the necessary raw materials should be acquired has been observed. The company has various sources of financing at its disposal to obtain the assets for raw material purchasing. As well as to provide raw materials, it is also necessary to reduce total additional purchase costs to a minimum. The mathematical model of this problem has been formulated in this paper as well and it has been applied to a real-life example.

The company should tend to secure such inventories which will meet the demand, bearing in mind at the same time not to create an excess of inventories so that it does not needlessly block its cash assets and therefore create the expenses in the form of interest for using these cash assets.

In the given case study, the company should use multiple sources of financing, because together with the adequate optimal combination of financing the orders, this turned out to be the best solution from the total costs perspective, as well as regarding flexibility in the management of inventories. Additionally, decision makers have better insight into possible scenarios when making decisions, which combined with their own personal preferences results in final decisions.

\section{REFERENCES}

[1] Abbasi, W. A., Wang, Z., \& Abbasi, D. A. (2017). Supply chain finance: generation and growth of new financing approach. Journal of Finance, 5(2), 50-57. DOI:10.15640/jfbm.v5n2a5

[2] Atanasov, N., Rakicevic, Z., Lecic-Cvetkovic, D., \& Omerbegovic-Bijelovic, J. (2014). An Approach to Stock Cover Indicator Adequacy. Management - Časopis za teoriju i praksu menadžmenta, 73, 41-47.

[3] Babich, V., \& Sobel, M. J. (2004). Pre-IPO operational and financial decisions. Management Science, 50(7), 935-948. Retrieved August 26, 2020, from http://www.jstor.org/stable/30047950

[4] Basu, R., \& Wright, J. N. (2010). Total supply chain management. London: Routledge. ISBN: 1136354115

[5] Buncic, D., \& Moretto, C. (2015). Forecasting copper prices with dynamic averaging and selection models. The North American Journal of Economics and Finance, 33, 1-38. DOI: 10.1016/j.najef.2015.03.002

[6] Buzacott, J. A., \& Zhang, R. Q. (2004). Inventory management with asset-based financing. Management Science, 50(9), 1274-1292. Retrieved August 26, 2020, from http://www.jstor.org/stable/30046233

[7] Caniato, F., Henke, M., \& Zsidisin, G. A. (2019). Supply chain finance: Historical foundations, current research, future developments. Journal of Purchasing and Supply Management, 25(2), 99-104. DOI: 10.1016/j.pursup.2019.02.002

[8] Chen, G. H., Zhao, Y., \& Su, B. (2017). Raw material inventory optimization for MTO enterprises under price fluctuations. Journal of Discrete Mathematical Sciences and Cryptography, 20(1), 255-270.

[9] Chen, L., Kok, A. G., \& Tong, J. D. (2013). The effect of payment schemes on inventory decisions: The role of mental accounting. Management Science, 59(2), 436-451. Retrieved August 26, 2020, from http://www.jstor.org/stable/23359490

[10] Chen, S. C., \& Teng, J. T. (2015). Inventory and credit decisions for time-varying deteriorating items with up-stream and down-stream trade credit financing by discounted cash flow analysis. European Journal of Operational Research, 243(2), 566-575. DOI: 10.1016/j.ejor.2014.12.007

[11] Chod, J. (2016). Inventory, risk shifting, and trade credit. Management Science, 63(10), 3207-3225. DOI:10.1287/mnsc.2016.2515 
[12] Cornuejols, G., Pena, J., \& Tutuncu, R. (2018). Optimization Methods in Finance. Cambridge University Press.

[13] Dada, M., \& Hu, Q. (2008). Financing newsvendor inventory. Operations Research Letters, 36(5), 569573. DOI: 10.1016/j.orl.2008.06.004

[14] Dye, C. Y. (2012). A finite horizon deteriorating inventory model with two-phase pricing and time-varying demand and cost under trade credit financing using particle swarm optimization. Swarm and Evolutionary Computation, 5, 37-53.

[15] GNU Linear Programing Kit. (2012). GLPK (GNU Linear Programming Kit). Retrieved May 25, 2020, from https://www.gnu.org/software/glpk/

[16] Gong, X., Chao, X., \& Simchi Levi, D. (2014). Dynamic inventory control with limited capital and short term financing. Naval Research Logistics (NRL), 61(3), 184-201. DOI:10.1002/nav.21576

[17] Huff, J., \& Rogers, D. S. (2015). Funding the Organization through Supply Chain Finance: A Longitudinal Investigation. Supply Chain Forum: An International Journal, 16(3), 4-17. DOI:10.1080/16258312.2015.11716348

[18] Jing, B., \& Seidmann, A. (2014). Finance sourcing in a supply chain. Decision support systems, 58, 1520.

[19] Katehakis, M. N., Melamed, B., \& Shi, J. J. (2016). Cash-Flow Based Dynamic Inventory Management. Production and Operations Management, 25(9), 1558-1575. DOI:10.1111/poms.12571

[20] Kouvelis, P., \& Zhao, W. (2012). Financing the newsvendor: supplier vs. bank, and the structure of optimal trade credit contracts. Operations Research, 60(3), 566-580.

[21] Lai, G., Debo, L. G., \& Sycara, K. (2009). Sharing inventory risk in supply chain: The implication of financial constraint. Omega, 37(4), 811-825. DOI:10.1016/j.omega.2008.06.003

[22] Lekkakos, S. D., \& Serrano, A. (2016). Supply chain finance for small and medium sized enterprises: the case of reverse factoring. International Journal of Physical Distribution \& Logistics Management, 46(4), 367-392. DOI: 10.1108/IJPDLM-07-2014-0165

[23] Marak, Z. R., \& Pillai, D. (2019). Factors, outcome, and the solutions of supply chain finance: review and the future directions. Journal of Risk and Financial Management, 12(1), 3. DOI:10.3390/jrfm12010003

[24] Moussawi-Haidar, L., \& Jaber, M. Y. (2013). A joint model for cash and inventory management for a retailer under delay in payments. Computers \& Industrial Engineering, 66(4), 758-767. DOI: 10.1016/j.cie.2013.09.021

[25] Njegomir, V., \& Demko-Rihter, J. (2015). The role and importance of insurance of business and supply chain interruptions. Management - journal for management theory and practice, 77, 53-60.

[26] Pal, B., Sana, S. S., \& Chaudhuri, K. (2014). Three stage trade credit policy in a three-layer supply chain-a production-inventory model. International Journal of Systems Science, 45(9), 1844-1868. DOI:10.1080/00207721.2012.757383

[27] Sana, S. S., \& Chaudhuri, K. S. (2008). A deterministic EOQ model with delays in payments and pricediscount offers. European Journal of Operational Research, 184(2), 509-533. DOI:10.1016/j.ejor.2006.11.023

[28] Sana, S. S., Ferro-Correa, J., Quintero, A., \& Amaya, R. (2018). A system dynamics model of financial flow in supply chains: a case study. RAIRO-Operations Research, 52(1), 187-204. https://doi.org/10.1051/ro/2017025

[29] Song, H., \& Song, Y. F. (2009). Impact of inventory management flexibility on service flexibility and performance: evidence from mainland Chinese firms. Transportation Journal, 7-19.

[30] Stevenson, W. (2005). Operations management, $8^{\text {th }}$ edition. McGraw-Hill/Irwin. ASIN: B007IUP4066

[31] Willing, N. (2020, December 10). Copper price forecast 2020 and beyond: will the market recover from Covid-19 disruptions? Capital.com. Retrieved from https://capital.com/copper-price-forecast-2020

[32] Yang, S. A., \& Birge, J. R. (2013). How inventory is (should be) financed: Trade credit in supply chains with demand uncertainty and costs of financial distress. DOI: $10.2139 / \mathrm{ssrn} .1734682$

[33] Zhang, Q., Dong, M., Luo, J., \& Segerstedt, A. (2014). Supply chain coordination with trade credit and quantity discount incorporating default risk. International Journal of Production Economics, 153, 352360. DOI: 10.1016/j.ijpe.2014.03.019

[34] Zhi, B., Wang, X., \& Xu, F. (2020). Impawn rate optimisation in inventory financing: A canonical vine copula-based approach. International Journal of Production Economics, 227, 107659. DOI: 10.1016/j.jpe.2020.107659 


\section{$3 / 1 / 1 / 1 / 1 / 1 / 1 / 1 / 1 / 1 / 1 / 1 / 1 / 1 / 1 / 1 /$ about the authors}

Kristina Stanojević

University of Belgrade, Faculty of Organizational Sciences, Serbia kristina.stanojevic992@gmail.com

Kristina Stanojević is currently a PhD candidate at the University of Belgrade, in Operation Research. She received a Bachelor's Degree in Operations Management, Masters' Degrees in Business analytics, and Environmental Management and Sustainable Development from the Faculty of Organizational Sciences.

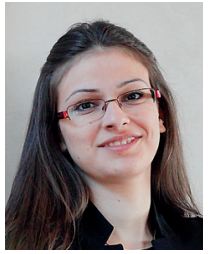

$\begin{array}{r}\text { Dragana Makajić-Nikolić } \\ \text { University of Belgrade, Faculty of Organizational Sciences, Serbia } \\ \text { dragana.makajic-nikolic@fon.bg.ac.rs }\end{array}$

Dr Dragana Makajić-Nikolić is an associate professor at the University of Belgrade, Faculty of Organizational Sciences, Serbia, where she acquired her Ph.D. (2012) degree in Operation Research. The areas of her research include: Mathematical Modelling, Optimization methods, Reliability and Risk Analysis.

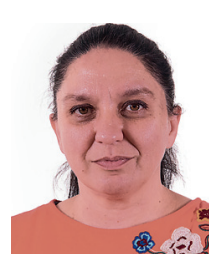

Goran Radovanović Ministry of Defence, University of Defence Belgrade, Serbia goran.radovanovic@vs.rs

Goran Radovanović, Ph.D., earned his M.Sc. and Ph.D. degrees (Military Management) from the Military Academy, University of Defence in Belgrade, in 2007 and 2016, respectively. Currently, he is Rector of the University of Defence, Belgrade, the Republic

of Serbia. He has published more than 40 research papers at national, international conferences and in national and international Journals. His research activity and interest are focused on Military management, Military developments, Terrorism and its Security Implications, International relations and world politics, as well as Methodology of Control in different fields.

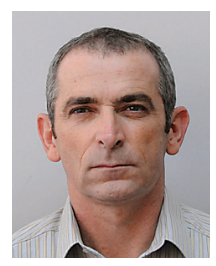

